Original Research Paper

\title{
Parameters Affecting the Performance of a Plate Heat Exchanger using the CFD
}

\author{
${ }^{1}$ Kutay Aydın, ${ }^{2}$ Onur Vahip Güler and ${ }^{2}$ Ali Keçebaş \\ ${ }^{I}$ Department of Mechanical Engineering, Amasya University, Amasya, Turkey \\ ${ }^{2}$ Department of Energy Systems Engineering, Muğla Sitkı Koçman University, Muğla, Turkey
}

Article history

Received: 22-06-2017

Revised: 05-08-2017

Accepted: $12-08-2017$

Corresponding Author:

Ali Keçebaş

Department of Energy Systems

Engineering, Muğla Sitk1

Koçman University, Muğla,

Turkey

Phone: +90 (252) 211-5471

Fax: +90 (252) 211-3150

E-mail: alikecebas@mu.edu.tr

\begin{abstract}
A plate heat exchanger is a type of heat exchangers that provides more surface area for heat transfer between two fluids. Plate heat exchangers are widely used for heat transfer applications in the industry. In addition, they are now widely used in many applications such as food processing, chemical reaction processes, heating and cooling applications in sectors such as petroleum. However, the design of plate heat exchangers is complicated by the large number of variables and geometries that affect its performance. A better heat exchanger design is to achieve a high heat transfer rate at low pumping power with low cost. In this study, the focus is on the research and development efforts of different plate materials, various fluid types, their flow regimes and the plate grooving angles on plate heat exchanger performance. For this purpose, the Computational Fluid Dynamics (CFD) is used. The results show that the heat efficiency is the best performing heat exchanger that can be designed as parallel- and counter-flow, geothermal fluid, titanium plate and $60^{\circ}$ groove angle from the point of view.
\end{abstract}

Keywords: Plate Heat Exchanger, Flow and Fluid Types, Plate Material, Groove Angle, Effectiveness

\section{Introduction}

In many engineering applications, heat transfer from the hot flow side to the cold flow side is accomplished through heat exchangers. One of the areas where the heat exchangers are most applied is geothermal applications. Geothermal applications can be divided into electricity generation and heating. Due to the chemical properties of the geothermal fluid, the heat exchangers are subject to pollution, corrosion, crusting, loss of thermal performance, productivity decline, maintenance and operating difficulties in heating applications. To solve these difficulties, the plate type heat exchangers are usually used.

The plate heat exchangers can be made compact by clamping them in the form of a fishbone into a carrier of wavy fine metal plates and a holding metal frame together. There are holes for fluid passage at the four corners of each metal plate. The hot and cold fluids flow through the space between the arrayed plates and they do not mix with each other. Due to the fishbone design, the plates become rigid, the distance between the plates becomes constant and the thermal performance improves. The plate heat exchangers are available in two types as the brazed and gasketed ones. Prazed type plate heat exchangers can operate at high temperature and pressure range and are low cost. However, prazed heat exchangers cannot be disassembled and cleaned and solder connections are susceptible to corrosion. In the heat exchangers with gasked plate, the plates can be dismounted and cleaning is thus facilitated. The use of suitable gaskets between the plates prevents mixing of fluids and leakage. The preferred reasons for the gasked plate heat exchangers include: (i) High heat transfer coefficient, (ii) High thermal efficiency, (iii) The higher efficiency and the smaller space occupancy compared to the shell and tube type heat exchangers, (iv) The cost is low because the plates are thin, (v) Less pollution, (vi) The possibility of mixing of fluids is low, (vii) No vibration, (viii) No hot and cold blind spots, (ix) Ease of maintenance and so on.

In order to solve the problems mentioned above in the plate type heat exchangers used in geothermal applications, there are many studies examining the optimum working conditions of the heat exchanger. In particular, Aktürk et al. (2011) experimentally and theoretically investigated the thermal performance of a plate heat exchanger under variable Reynolds numbers in their work. Theirs results are showed that the higher the Reynolds number of the stream, the higher the thermal 
performance. Bansal et al. (2000) researched the calcium sulfate accumulation for two different plate heat exchanger geometries in terms of flow rate, flow volume and surface temperature parameters. They pointed out that there is a strong relationship between the trend in the fluid system and the plate design. Grijspeerdt et al. (2003) examined the two- and three-dimensional behaviors of fluids for two grooved plates in detail by using Computational Fluid Dynamics (CFD) analysis in the plate heat exchangers used during milk production application. They have shown that fluid behavior calculations are a very important aid for optimum plate heat exchanger design. Gut and Pinto (2003) mathematically simulated a gasket heat exchanger in an algorithmic form. They determined the configuration as channel number, number of fluid passages, feed connection point and fluid flow type and tried to determine optimum heat exchanger design with configurations using this model. As a result of the simulation, they found the temperature graphs, thermal efficiencies, total heat transfer coefficient and pressure drops of all the channels and reached the total heat transfer coefficient. Zhu and Zhang (2004) examined the materials, sizing and flow rates required for optimum design of a plate heat exchanger operating in a geothermal heating system. In these investigations, they determined the optimum design factors of the heat exchanger by comparing the high thermal efficiency, the low pressure loss, the best flow rate and the working temperatures with the actual design data. Experiments by Kim and Kim (2005) have shown that the optimum flat plate finned tube heat exchangers have been tested on the wing slopes in their design and have tested different wing pitches, number of tubes and pipe alignment of twenty two heat exchangers. As a result of the studies, they reached the finding that they provided $10 \%$ more efficiency without bringing the pipes in a stepped form. Benli et al. (2006) have experimentally investigated and compared the thermal performances of flat/star surface geometry and count/parallel flow plate heat exchangers. They found that the star surface geometry heat exchanger has $12-65 \%$ more thermal performance than the flat surface geometry. As the star geometry creates additional tubularity, the result is that the loss of the pressure is more than $200-300 \%$ of the star geometry.

Jain et al. (2007) have been carried out experimental and numerical studies for the flow in single pass chevron plate heat exchanger. The simulations were performed by commercial CFD software via Fluent. The different turbulence models such as RNG k- $\varepsilon$ and Realizable k- $\varepsilon$ has been tested in their study. Hot and cold fluids are modeled on realistic conditions, but only a $60^{\circ}$ chevron angle plate has been tried. Realizable k- $\varepsilon$ turbulence model achieved the best results with non-equilibrium wall boundary condition. Kanaris et al. (2009) studied on increase of the heat transfer by plate grooves of CFD codes in plate heat exchangers andthe performance of determining the character of the flow. They compared the numerical results obtained in the study with the experimental results. They used the SST k- $\omega$ turbulence model for simulation. The CFD codes are very effective for optimum design of plate heat exchanger in different geometric configurations. Therefore, the improvement of heat transfer and the increase of pressure drop in curved plate heat exchangers were observed. Han et al. (2010) investigated numerically and experimentally under different temperature, pressure and velocity parameters with a gasket plate heat exchanger. The calculation area consists of convoluted channels and the SST $k-\omega$ is chosen as the turbulence model. They found a maximum deviation of $35 \%$ when comparing numerically and experimentally obtained temperature, pressure and velocity loss changes. The reasons for this deviation amount are: the flow resistance zones in the plates is smaller than the real ones, the accuracy rate of the glass flow meter used in experiments is low, no stable flow of series-connected pumps used in experiments is and some factors are assumed to be negative in simulations. Şencan et al. (2010) experimentally designed and manufactured a heating-cooling system using a plate heat exchanger. They determined the optimum temperatures and flow rate of fluids circulating in the heat exchangers under different operating conditions. O'Halloran and Jokar (2011) conducted empirical and numerical analyzes using gasked plate heat exchangers. Numerical analysis was carried out for a 3-brazed corrugated plate heat exchanger with different chevron angles. The chevron angles of the simulated plates were $60^{\circ} / 60^{\circ}, 27^{\circ} / 60^{\circ}$ and $27^{\circ} / 27^{\circ}$. Fluent software was used to analyze for different temperature and different speed boundary conditions. Aktürk et al. (2011) experimentally and theoretically investigated the thermal performance of a plate heat exchanger under variable Reynolds numbers. Thus, they reported that as the flow Reynolds number increases, the thermal performance increases. Kan (2014) investigated optimum operating conditions of a plate heat exchanger with $30^{\circ}, 45^{\circ}$ and $60^{\circ}$ of grooving angles at $0.2 \mathrm{~kg} / \mathrm{s}, 0.3 \mathrm{~kg} / \mathrm{s}$ and $0.43 \mathrm{~kg} / \mathrm{s}$ of flow rates by the CFD analysis. As a result, $0.2 \mathrm{~kg} / \mathrm{s}$ flow rate and $60^{\circ}$ grooving angle models achieved the best thermal performance. Khoshvaght-Aliabadi et al. (2015) investigated the performance of the heat exchanger by comparing the experimental and CFD analysis data of the turbulent-wing heat exchanger. As a result, the heat transfer performance increased between 26.2 and 58.3\% and the biggest factor increasing the thermal performance was the wing height and then the wing angle.

In literature, it is available in studies using different optimization methods. For example; Riverol and Cooney (2005) tried to estimate the critical time, mean heat transfer coefficient and layer thickness using artificial neural networks in plate heat exchangers. The results of 
their work have shown that the results are appropriate for current industry practice techniques. Chen and Chen (2006) investigated the effects on heat transfer and pressure drop of heat exchanger of five experimental factors consisting of flow rate, number of blades, blade thickness, number of pipes, number of plates and plate angle using the Taguchi method. The amount of fluid, number of blades, blade thickness and number of plates were found to affect the performance of the heat exchanger as a basis and they determined that the parameters outside them played an important role in the design of the optimum heat exchanger. Freund and Kabelac (2010) have tried to determine the regional heat transfer coefficients in the plate heat exchanger with infrared thermal camera and CFD analysis. They found that different heat transfer coefficients were formed in different regions of the heat exchanger and that they increased or decreased in direct proportion to the Reynolds number. In addition, they have come to the conclusion that the most suitable heat exchanger geometries can be found by CFD analysis in order to make CFD analyzes using different Reynolds turbulence models.

Due to the widespread application area of the plate heat exchangers, it maintains its originality in the literature studies. Optimization studies of plate heat exchangers are still continuing in Turkey and in the world today. The difference of this study from the studies in the literature is the plate heat exchanger materials used in geothermal applications, the use of geothermal fluid as a fluid and a different approach to geometric modeling. In this study, 8 threedimensional computer-assisted models are considered, with $15^{\circ}, 30^{\circ}, 45^{\circ}$ and $60^{\circ}$ of grooved angles, parallel/counter flow and cross/counter flow of the plate heat exchangers. In these models, the following principles have been taken into account: (i) the thermodynamic characteristics are determined by the CFD method, (ii) the AISI 316 stainless steel and titanium, which are used in geothermal applications as plate material, are selected and (iii) water and geothermal fluid are used as fluid type. Therefore, 32 simulation models have been prepared and these models have been examined numerically. Models in the direction of the data obtained from numerical analysis are compared with each other. As a result, the optimum conditions for maximizing the performance of the plate heat exchanger have been investigated.

\section{Material and Method}

\section{Computer Aided Modeling (CAM)}

Technical measures of the plate heat exchanger considered in the study are given in Table 1. So that the Computer Aided Modelings (CAMs) can be easily solved in the computer for Computational Fluid Dynamics (CFD) analysis. The single plate was made by simply taking the $35 \times 35 \mathrm{~mm}$ square samples from the middle zone of the shape by reducing it to simple as single hot and single cold flow so that the computer can solve it easily (Fig. 1a). The numerical analysis samples of the plate heat exchanger were modeled as $\beta$-groove angles of $15^{\circ}, 30^{\circ}, 45^{\circ}$ and $60^{\circ}$ (Fig. 1b), parallelcounter (Fig. 2) and cross-counter (Fig. 3) flow types.

The movements of the fluids may be diagonal or parallel to each other (Fig. 4). The plate surfaces are shaped to allow fluids to meet at more surfaces. Therefore, the fluids circulate in narrow and complex geometric channels. With this complicated reason, the flow is usually turbulent. The thermal performance is increased by means of turbulent or mixed flow. The parallel or cross flow of the water flow directions are closely related to the thermal efficiency of the heat exchanger. Thanks to the horizontal, vertical or angled productions of the water circulation channels formed on the plate surfaces, the water flows can be supported by the parallel flow and the cross flow, as well as the mixed flow, so that the thermal efficiency can be maximized (Şahan, 2001).

\section{Operating Parameters and Boundary Conditions}

The measurements of the plate heat exchanger samples and the initial and boundary conditions of the numerical analysis are shown in Table 1. The heat transfer coefficients of the fluids and the specific heat of the geothermal fluid are taken from the results obtained from the experimental work done by İskender (2010). As the heat transfer coefficient of the geothermal fluid, the average heat transfer coefficient of saturated salt water, which is similar to the chemistry of this fluid, has been accepted (Table 2).

\section{Thermal Effectiveness}

The heat transfer effectiveness $(\varepsilon)$, which is an important factor in comparing the heat exchangers with each other, is the ratio of the actual heat transfer rate at a heat exchanger to the maximum possible heat transfer rate, as given below:

$\varepsilon=\frac{\dot{Q}_{\text {real }}}{\dot{Q}_{\text {max }}}$

The actual heat transfer rate $\left(\dot{Q}_{\text {real }}\right)$ in a heat exchanger is found by the energy balance of hot and cold fluids:

$$
\begin{aligned}
& \dot{Q}_{\text {real }}=C_{\text {hot }}\left(T_{\text {hot }, \text { in }}-T_{\text {hot out }}\right) \\
& \dot{Q}_{\text {real }}=C_{\text {cold }}\left(T_{\text {cold, out }}-T_{\text {cold, in }}\right)
\end{aligned}
$$


Kutay Aydın et al. / Energy Research Journal 2017, 8 (2): 22.31

DOI: 10.3844/erjsp.2017.22.31

Table 1. Sample measurements and operating conditions

\begin{tabular}{|c|c|}
\hline Sample sizes, $\mathrm{mm}$ & $35 \times 35$ \\
\hline Total thickness of plate, $\mathrm{mm}$ & 3 \\
\hline Wall thickness of plate, mm & 0.5 \\
\hline Number of plate & 1 \\
\hline Plate materials & AISI316 stainless steel titanium \\
\hline Mass flow rate of hot fluid, $\dot{m}_{h o t}, \mathrm{~kg} / \mathrm{s}$ & 0.001 \\
\hline Mass flow rate of cold fluid, $\dot{m}_{\text {cold }}, \mathrm{kg} / \mathrm{s}$ & 0.001 \\
\hline Inlet temperature of hot fluid, $T_{h o t, i n},{ }^{\circ} \mathrm{C}$ & 90 \\
\hline Inlet temperature of cold fluid, $T_{\text {cold,in }},{ }^{\circ} \mathrm{C}$ & 40 \\
\hline Inlet pressure of hot fluid, $P_{\text {hot in }}$ bar & 2 \\
\hline Inlet pressure of cold fluid, $P_{\text {cold,in, }}$, bar & 2 \\
\hline Heat transfer coefficient of water, $k_{w}, \mathrm{~W} / \mathrm{mK}$ & 0.65 \\
\hline Heat transfer coefficient of brine, $k_{\mathrm{b}}, \mathrm{W} / \mathrm{mK}$ & 0.49 \\
\hline Specific heat of water, $c_{p, w, \text { ave }}, \mathrm{kj} / \mathrm{kgK}$ & 4.18 \\
\hline Specific heat of brine, $c_{p, b \text { ave }} \mathrm{kj} / \mathrm{kgK}$ & 3.11 \\
\hline Heat transfer coefficient of $\mathrm{A}_{\mathrm{ISI} 316}, \mathrm{k}_{\mathrm{AISI} 316}, \mathrm{~W} / \mathrm{mK}$ & 14.08 \\
\hline Heat transfer coefficient of Titanium, $k_{T 1}$, W/mK & 21.9 \\
\hline
\end{tabular}

Table 2. Heat transfer coefficients of water and saturated salt water solution in atmospheric pressure (İskender, 2010)

\begin{tabular}{|c|c|c|c|c|c|c|c|c|c|c|c|}
\hline $\operatorname{are}\left({ }^{\circ} \mathrm{C}\right)$ & 0 & 10 & 20 & 30 & 40 & 50 & 60 & 70 & 80 & 90 & 100 \\
\hline & 0 & 0. & & & & & & 0. & 0 & 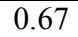 & 0.68 \\
\hline Heat & 0.44 & 0.45 & 0.45 & 0.46 & 0.47 & 0.48 & 0.49 & 0.49 & 0.50 & 0.51 & .52 \\
\hline
\end{tabular}

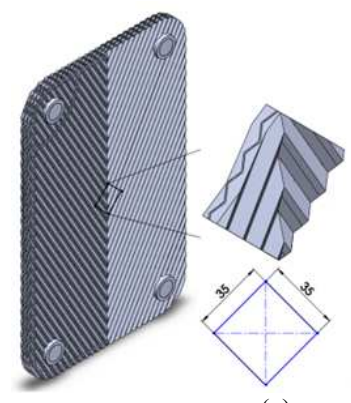

(a)

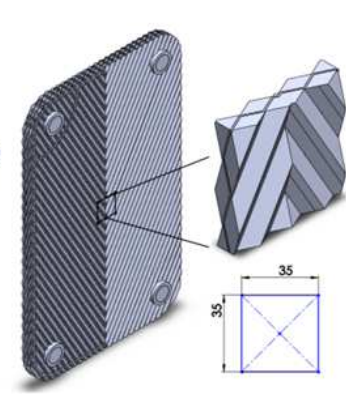

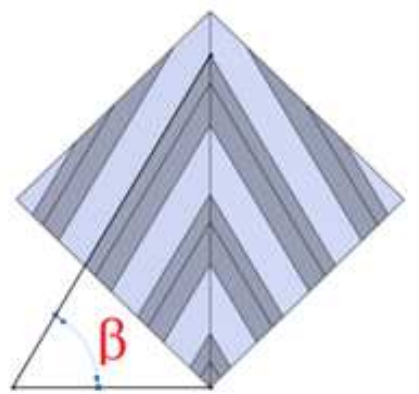

(b)

Fig. 1. The view of (a) model and analysis samples and (b) plate groove angle, $\beta$, of the plate heat exchanger
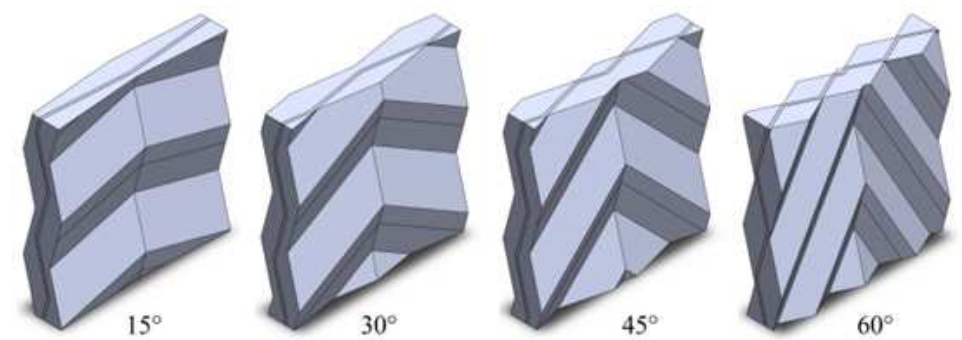

Fig. 2. Parallel and counter-flow samples at different groove angles
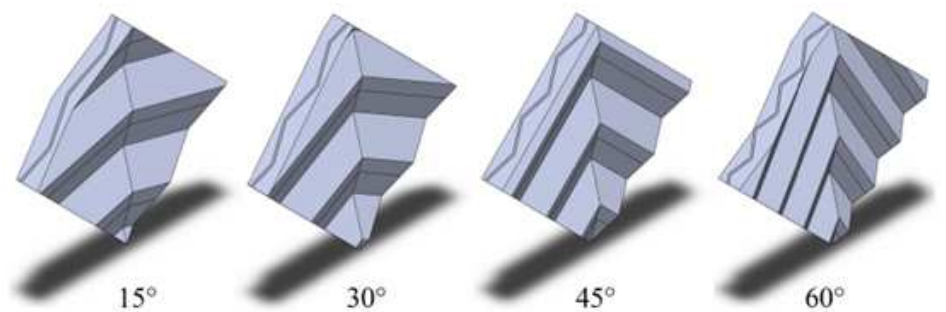

Fig. 3. Cross-flow and counter-flow samples at different groove angles 


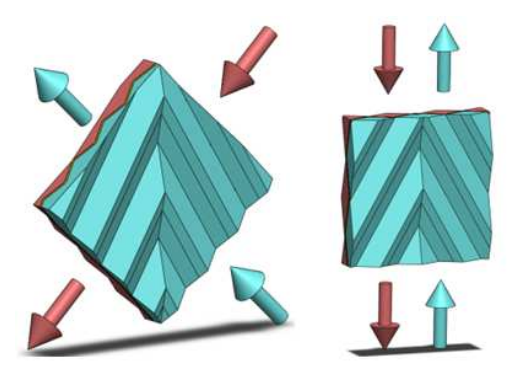

Fig. 4. Cross and parallel-flows motions for counter-flow of the hot and cold fluids

where, $C_{\text {hot }}$ ve $C_{\text {old }}$ are the thermal capacity rates of hot and cold fluids, respectively. They can be clearly written as in the following expression:

$$
\begin{aligned}
& C_{\text {hot }}=\dot{m}_{\text {hot }} c_{p, h o t, \text { in }} \\
& C_{\text {cold }}=\dot{m}_{\text {cold }} c_{p, \text { cold , in }}
\end{aligned}
$$

The maximum heat transfer rate $\left(\dot{Q}_{\text {real }}\right)$ that a heat exchanger may have is found by multiplying the thermal capacity rates $\left(C_{\text {hot }}, C_{\text {cold }}\right)$ by the smaller $\left(C_{\min }\right)$ and the maximum temperature difference:

$$
\dot{Q}_{\max }=C_{\min }\left(T_{\text {hot, in }}-T_{\text {cold ,in }}\right)
$$

When only water is used as the fluid in the analysis, the relation between the thermal capacity rates is $C_{\min }=$ $C_{\text {hot }}=C_{\text {cold }}$. When geothermal fluid is used as hot fluid and water is used as cold fluid, it is $C_{\min }=C_{h o t}$. The thermal effective nesses for both conditions are given below (Çengel and Ghajar, 2015):

$$
\begin{aligned}
& \varepsilon=\frac{\dot{Q}_{\text {reel }}}{\dot{Q}_{\text {max }}}=\frac{C_{\text {hot }}\left(T_{\text {hot }, \text { in }}-T_{\text {hot }, \text { out }}\right)}{C_{\text {min }}\left(T_{\text {hot }, \text { in }}-T_{\text {cold }, \text { in }}\right)} \\
& \varepsilon=\frac{\left(T_{\text {hot }, \text { in }}-T_{\text {hot, out }}\right)}{\left(T_{\text {hot }, \text { in }}-T_{\text {cold }, \text { in }}\right)}
\end{aligned}
$$

\section{Computational Fluid Dynamics (CFD) Modeling}

In this study, numerical analyzes are solved by using finite element method, three dimensional, time independent and combined (conduction and convection) heat transfer approach.

\section{Mass, Momentum and Energy Conservations}

The finite volume method is based on the principle of finding the solution of the problem by dividing the geometry to be solved into solutions for each of these parts and then combining these solutions. The finite volume method uses a control volume-based technique to transform conservation equations (Table 3) into numerically solvable systems of algebraic equations. This technique involves obtaining the discrete equations that provide the control volume for the variables as a result of taking the integration of conservation equations for each control volume. The variables related to the iteration of linear systems of equations such as velocity, pressure and temperature, obtained by linearizing the discrete equations, are updated until the given convergence measure is met. For optimum network structure to be prepared, more frequent network structure should be established in regions where speed, pressure and temperature changes are excessive (Karabulut et al., 2013) for this reason, the hot and cold flow volumes between the plates are the most frequent parts of the mesh structure. An example is shown in Fig. 5.

In numerical analysis, flow and heat transfer solutions are solved by the equations derived from the laws of mass (continuity equation), momentum and energy conservation independently from time. These equations are shown in Table 3. Where $\rho$ is the density, $\mu$ is the dynamic viscosity, $p$ is the pressure, $k$ is the thermal conductivity, $T$ is the temperature, $c_{p}$ is the specific heat and $u, v, w$ are the velocities in the $x, y$ and $z$ directions, respectively.

\section{Turbulence Modeling}

The most important factor in achieving heat transfer in the plate heat exchangers is turbulent flow due to complex geometry. Therefore, the turbulence model used in the analyzes has been chosen at an advanced level. In this study, Reynolds Stress Model which is a model that can be physically counted as turbulence model is used. The Reynolds stress model has the most appropriate modeling potential to accurately solve complex flows and takes into account flow curvature, rotation and high-stress ratios when solving. The Reynolds stress model equations are shown in Table 4. Where $\rho$ is density, $\mu$ is dynamic viscosity, $p$ is pressure and $u_{i}, u_{j}, u_{k}$ are velocity components.

\section{Wall Functions Modeling}

Wall functions are used to relate the viscosity effects between the walls and the turbulence zone. With the use of these functions, the necessity of modifying the turbulence models ceases to exist. In the case of high Reynolds number flows, the wall functions approach is used extensively because of the fact that the viscous effects that change the solution variables very quickly around the wall are not necessary for solutions and give numerically correct results. Thus, there is no need to resolve the viscosity-sensitive region near the wall by dividing it into frequent nets and a bridge is established between the wall and the turbulent region (Ansys Inc. 2013; Kaya and Karagöz, 2007). 


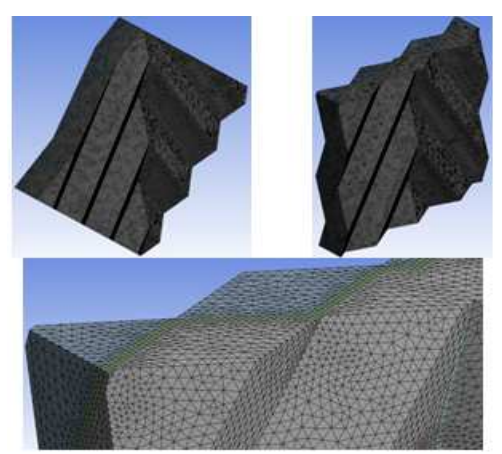

Fig. 5. Example mesh tissues of the plate

\section{Standart Wall Function}

It has a widespread use in numerical analysis and usually gives accurate results. However, if there is a high Reynolds flow in the areas close to the wall, deviations from the results obtained using the standard wall function are observed and are removed from consistent results (Ansys Inc. 2013; Gong and Wang, 2010).

\section{Nonequilibrium Wall Function}

It divides the area near the wall into two layers and analyzes the high Reynolds number flow effects that the standard wall function does not meet. It is used to achieve the most consistent result in high reynold number flow models and thermal performance analyzes (Ansys Inc. 2013; Gong and Wang, 2010).

Kaya and Karagöz (2007) have solved the conservation equations of flow with different turbulence models at a certain inlet velocity while studying the investigation of turbulence models in the turbulent flows and the axial and tangential velocity profiles and the pressure drop values obtained by Gong and Wang (2010), which are experimental studies with the same geometric model, are compared. According to these comparisons, the most suitable turbulence and wall function models for the vortex flows are the Nonequilibrium wall function Reynolds stress model. In this study, the Nonequilibrium wall function Reynolds stress model was used for numerical analysis.

Table 3. 3D Navier-Stokes, energy and momentum conservation equations (Ansys Inc. 2013)

\begin{tabular}{ll}
\hline Formules & Equations \\
\hline Continuity momentum & $\frac{\partial u}{\partial x}+\frac{\partial v}{\partial y}+\frac{\partial w}{\partial z}=0$ \\
x-coordinate & $\rho\left(u \frac{\partial u}{\partial x}+v \frac{\partial u}{\partial y}+w \frac{\partial u}{\partial z}\right)=-\frac{d p}{d x}+\mu\left(\frac{\partial^{2} u}{\partial x^{2}}+\frac{\partial^{2} u}{\partial y^{2}}+\frac{\partial^{2} u}{\partial z^{2}}\right)$ \\
y-coordinate & $\rho\left(u \frac{\partial v}{\partial x}+v \frac{\partial v}{\partial y}+w \frac{\partial v}{\partial z}\right)=-\frac{d p}{d y}+\mu\left(\frac{\partial^{2} v}{\partial x^{2}}+\frac{\partial^{2} v}{\partial y^{2}}+\frac{\partial^{2} v}{\partial z^{2}}\right)$ \\
z-coordinate & $\rho\left(u \frac{\partial w}{\partial x}+v \frac{\partial w}{\partial y}+w \frac{\partial w}{\partial z}\right)=-\frac{d p}{d z}+\mu\left(\frac{\partial^{2} w}{\partial x^{2}}+\frac{\partial^{2} w}{\partial y^{2}}+\frac{\partial^{2} w}{\partial z^{2}}\right)$ \\
Energy & $u \frac{\partial T}{\partial x}+v \frac{\partial T}{\partial y}+w \frac{\partial T}{\partial z}=\left(\frac{k}{\rho c_{p}}\right)\left(\frac{\partial^{2} T}{\partial x^{2}}+\frac{\partial^{2} T}{\partial y^{2}}+\frac{\partial^{2} T}{\partial z^{2}}\right)$ \\
\hline
\end{tabular}

Table 4. Reynolds stress model equations for incompressible fluid, continuous regime and force-free state (Ansys Inc. 2013)

\begin{tabular}{|c|c|c|}
\hline Formules & Equations & No \\
\hline Reynolds stress transfer & $\frac{\partial}{\partial t}\left(\rho \overline{u_{\imath}^{\prime} u_{j}^{\prime}}\right)=\frac{\partial}{\partial x_{k}}\left(\rho u_{k} \overline{u_{\imath}^{\prime} u_{j}^{\prime}}\right)=D_{t, i j}+D_{i, j}+S_{i, j}+\Phi_{i, j}+E_{i, j}$ & $(14)$ \\
\hline \multicolumn{3}{|c|}{ The terms on the right side of the equation in turn are } \\
\hline Turbulent diffusion term & $D_{t, i j}=-\frac{\partial}{\partial X_{k}}\left[\rho u_{i}^{\prime} \overline{u_{j}^{\prime} u_{k}^{\prime}}+p\left(\overline{\delta_{k j} u_{i}^{\prime}+\delta_{i k} u_{j}^{\prime}}\right)\right]$ & $(15)$ \\
\hline Molecular diffusion term & $D_{t, i j}=-\frac{\partial}{\partial X_{k}}\left(\mu \frac{\partial}{\partial X_{k}} \overline{u_{i}^{\prime} u_{j}^{\prime}}\right)$ & $(16)$ \\
\hline Turbulent stress production term & $S_{i, j}=\rho\left(\overline{u_{i}^{\prime} u_{k}^{\prime}} \frac{\partial}{\partial X_{k}} \overline{u_{j}^{\prime} u_{k}^{\prime}} \frac{\partial u_{i}}{\partial X_{k}}\right)$ & $(17)$ \\
\hline Pressure-strain term & $\Phi_{i, j}=\rho\left(\overline{\frac{\partial u_{i}^{\prime}}{\partial X_{j}}+\frac{\partial u_{j}^{\prime}}{\partial X_{i}}}\right)$ & $(18)$ \\
\hline Dissipation term & $E_{i, j}=-2 \mu\left(\overline{\frac{\partial u_{i}}{\partial x_{j}}+\frac{\partial u_{j}}{\partial x_{i}}}\right)$ & (19) \\
\hline
\end{tabular}




\section{Results and Discussion}

Computational Fluid Dynamics (CFD) analyzes were performed on the ANSYS-Fluent program. From the simulated 8 plate heat exchanger samples, the total heat transfer area, the total heat flow from the hot flow direction to the cold flow field and the outlet temperatures of the fluids were obtained in the cases of the variable flow model and the groove angles.

The heat transfer area, total heat flow, mean outlet temperatures of the fluids and their effectiveness are shown in Table 5 for cross and counter flow and Table 6 for parallel and counter flow, according to the groove angles of the samples. Generally, as seen from these two tables, the values of all given parameters increase as the groove angle increases. Compared to the flow regimes, as can be seen from the tables, the heat flux increases by $4.54 \%$ and the thermal efficiency increases by $10.71 \%$ on average in both flow regimes as the groove angle increases. The inlet and outlet temperature differences of the fluid are approximately $12.79 \%$ greater in the parallel and counter flow than those in the cross and counter flow. Numerical differences between the heat fluxes in the tables are less sensitive to flow regime and groove angle sensitivities than the fluid inlet and outlet temperature differences. This is why a small value of $0.001 \mathrm{~kg} / \mathrm{s}$ is selected for input flow rate of the fluid. The reason for the small selection of fluid inlet flow rate is that the simulated samples are limited to a small portion of the plate heat exchanger, such as only one plate, one hot and one cold fluid volume, so that the analysis cannot be performed on the actual plate heat exchanger sizes and actual operating parameters. However, the temperature changes at the level were clearly visualized numerically (Table 5 and 6) and visually (Table 7) according to the fluid inlet temperatures. The results were obtained in expected sensitivity from the study.

The reason for this size limitation is the larger the dimension of the figure to be analyzed the more the number of end elements to be iterated increases, the over-constraining computer hardware for solution and the impossible solution. Thus, in this study, a simplified partial section of the plate heat exchanger is simulated.

In Table 5 for the cross-counter flow, it seen that the heat flow, the inlet and outlet temperatures and the effectiveness are high according to the geothermal fluid (brine) of the water. Due to the chemical composition of the brine, such heat transfer performance difficulties are experienced. However, it seems to be more appropriate to use titanium as the heat exchanger material for the brine. For example, in
Table 5 the effectiveness for AISI 316 and the titanium material of heat exchangers in $45^{\circ}$ groove angle and brine fluid are 0.514 and 0.517, respectively. This is a result of the heat transfer coefficient of titanium being higher than the other one.

The results given in Table 6 are quite similar to Table 5 for parallel-counter flow. However, a comparison must also be made between the crosscounter flow and the parallel-counter flow. For the same groove angle and both fluids, the heat flux for titanium as plate material appears to increase heat flux by $1-2 \%$ in the cross-counter flow regime and $1-5 \%$ in the parallel-counter flow regime according to that for the AISI 316. For all groove angles, same plate material and both flow regimes, the thermal efficiency of the water increases by $10-13 \%$ in the cross-counter flow and $4-12 \%$ in the parallel-counter flow, while the thermal flux of the water decreases by $10-15 \%$ compared to the geothermal flow. The reason for this is that the specific heat of the brine is $25 \%$ smaller than pure water. As the specific heat is small, the heat flow in the analyzes using the brine is reduced because it reduces the amount of heat required for the unit temperature increase. Based on the results in Table 5 and 6 , the percentage increase in the total heat transfer area is shown in Fig. 6, when the groove angle increases. However, in geothermal flow as can be seen in Fig. 7, its thermal efficiency increases as the cold fluid temperature difference decreases and the hot fluid temperature difference increases.

When thermal efficiencies are examined, in the same plate material the water is $11.23 \%$ more in cross-counter flow than that of brine and $8.70 \%$ more in parallel-counter flow. When the same fluid is used, the titanium has an average of $0.96 \%$ of cross-counter flow and an average of $1.79 \%$ of parallel-counter flow relative to AISI 316. When compared to the flow regimes, the thermal efficiency increases by an average of $10.71 \%$ over the cross-counter flow in the parallel-counter flow. In addition, as can be seen from the findings in Table 5 and 6, they are the same as the graphs of visual temperature change in Table 7 due to the low flow rate, although the plate material and fluid type change. For this reason, in Table 7 , the visual graphs of analysis results with cross-counter flow and parallel-counter flow regressions, water flow and AISI 316 steel plates are given. In here, parallel-counter flow as flow regime, titanium as plate material and water as fluid appears to improve the heat transfer of the plate heat exchangers. When the effectiveness of the heat exchanger is examined, it is seen that the parallel-counter flow and the titanium are more effective but the brine is more effective than the water. 


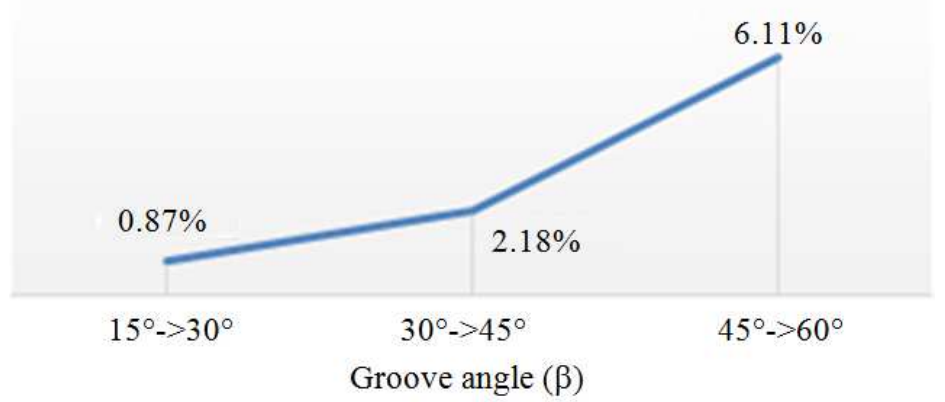

Fig. 6. Percentage increase of heat transfer area by groove angle

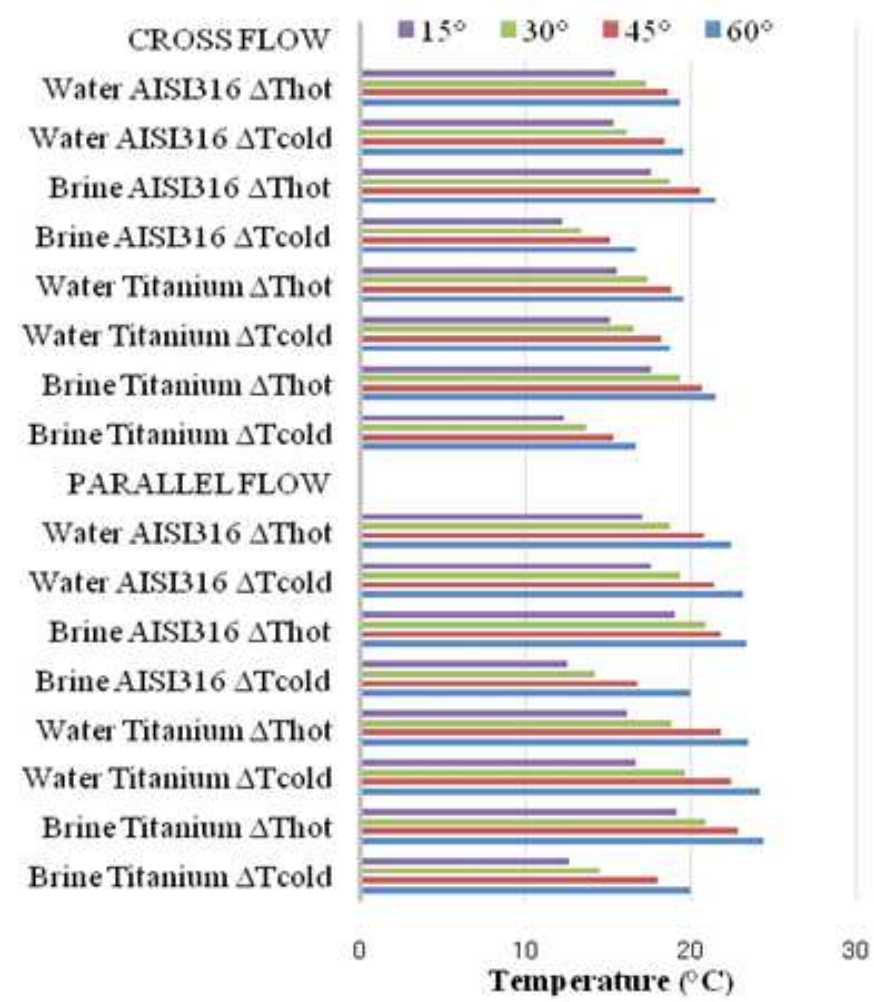

Fig. 7. A graph that compares the inlet and outlet temperature differences of the hot and cold fluids

\section{Conclusion}

In this study, the change of working conditions of a plate heat exchanger used in geothermal applications depending on flow regime, plate groove angle $(\beta)$, fluid type and plate material was investigated by 3dimensional CFD analysis. It has been found that the best operating conditions for heat transfer are a plate heat exchanger model with the parallel-counter flow, water-fluid, titanium plate and $60^{\circ}$ groove angle. This work has created a database for future numerical and experimental studies.

\section{Author's Contributions}

Kutay Aydın: Conducted the solid modelling and made the CFD analysis.

Onur Vahip Güler: Discussed the results and contributed to the writing of the manuscript.

Ali Keçebaş: Designed the research plan, organized the study and edited the whole work.

\section{Ethics}

This article is original and contains unpublished material. The corresponding author confirms that all of 
the other authors have read and approved the manuscript and no ethical issues involved.

\section{References}

Aktürk, F., N.S. Uzol, S. Aradağ, S. Kakaç and U. Atamtürk, 2011. Plakalı 1sı değiştirgeçlerinde plakaya bağımlı 1sı transferinin deneysel incelenmesi ve modellenmesi. Proceedings of the 10th National Installation Engineering Congress, Apri. 13-16, Izmir, Turkey, pp: 1995-2009.

Bansal, B., H. Müller-Steinhagen and X.D. Chen, 2000. Performance of plate heat exchangers during calcium sulphate fouling-investigation with an inline filter. Chem. Eng. Processing Process Intensification, 39: 507-519.

Grijspeerdt, K., B. Hazarika and D. Vucinic, 2003. Application of computational fluid dynamics to model the hydrodynamics of plate heat exchangers for milk processing. J. Food Eng., 57: 237-242.

Gut, J.A.W. and J.M. Pinto, 2003. Modeling of plate heat exchangers with generalized configurations. Int. J. Heat Mass Transfer., 46: 2571-2585.

Zhu, J. and W. Zhang, 2004. Optimization design of Plate Heat Exchangers (PHE) for geothermal district heating systems. Geothermics, 33: 337-347.

Kim, Y. and Y. Kim, 2005. Heat transfer characteristics of flat plate finned-tube heat exchangers with large fin pitch. Int. J. Ref., 28: 851-858.

Benli, H., H. Gül and A. Durmuş, 2006. Investigation of heat transfer of single pass plate type heat exchangers having different surface profiles. Sci. Eng. J. Firat Univ., 18: 569-575.

Jain, S., A. Joshi and P.K. Bansal, 2007. A new approach to numerical simulation of small sized plate heat exchangers with chevron plates. J. Heat Transfer, 129: 291-297.

Kanaris, A.G., A.A. Mouza and S.V. Paras, 2009. Optimal design of a plate heat exchanger with undulated surfaces. Int. J. Thermal Sci., 48: 1184-1195.

Han, X.H., L.Q. Cui, S.J. Chen, G.M. Chen and Q. Wang, 2010. A numerical and experimental study of chevron, corrugated-plate heat exchangers. Int. Commun. Heat Mass Transfer, 37: 1008-1014.

Şencan, A., R. Selbaş and B. Kılıç, 2010. Experimental analysis of plate heat exchangers used in heating and cooling applications. Tübav Bilim Dergisi, 3: 35-44.

O'Halloran, S. and A. Jokar, 2011. CFD simulation of single-phase flow in plate heat exchangers. ASHRAE Trans.

Kan, M., 2014. Plate heat exchangers as a compact design and optimization of different channel angles. PhD Thesis, Süleyman Demirel University.

Khoshvaght-Aliabadi, M., S. Zangouei and F. Hormozi, 2015. Performance of a plate-fin heat exchanger with vortex-generator channels: 3D-CFD simulation and experimental validation. Int. J. Thermal Sci., 88: 180-192.

Riverol, C. and J. Cooney, 2005. A knowledge-based pattern recognition approach for the prediction of bubble size distribution in Newtonian fluids at high pressure. Chem. Eng. J., 112: 131-135.

Chen, D.C. and C.F. Chen, 2006. Use of Taguchi method to develop a robust design for the shape rolling of porous sectioned sheet. J. Mater. Processing Technol., 177: 104-108.

Freund, S. and S. Kabelac, 2010. Investigation of local heat transfer coefficients in plate heat exchangers with temperature oscillation IR thermography and CFD. Int. J. Heat Mass Transfer, 53: 3764-3781.

Şahan, A.M., 2001. Jeotermal doğrudan isıtma sistemlerinde plakalı isı değiştirgeçleri. Proceedings of the 5th National Installation Engineering Congress, Oct. 3-6, Izmir, Turkey, pp: 187-200.

İskender, A., 2010. Investigation of thermodynamic properties of solar ponds. PhD Thesis, Çukurova University, Adana.

Çengel, Y.A. and A.J. Ghajar, 2015. Isı ve Kütle Transferi: Esaslar ve Uygulamalar. 4th Edn., Palme, Ankara, ISBN-10: 6053552879, pp: 908.

Ansys Inc. 2013. Fluent Theory Guide Release15.0, Canonsburg, PA, USA.

Karabulut, K., E. Buyruk, F. Kılınç and Ö.O. Karabulut, 2013. Farklı geometrilerden oluşan kanatçıklı plakalı 1S1 değiştiricileri için 1S1 transferinin üç boyutlu sayısal olarak incelenmesi. Proceedings of the 11 th National Installation Engineering Congress, Apri. 17-20, Izmir, Turkey.

Kaya, F. and İ. Karagöz, 2007. Investigation into the suitability of turbulence models in swirling flows. Uludag Univ. J. Faculty Eng., 12: 85-96.

Gong, A.L. and L.Z. Wang, 2010. Numerical study of gas phase flow in cyclones with the repds. Aerosol Sci. Technol., 38: 506-512.

\section{Nomenclature}

A

C

$\mathrm{c}_{\mathrm{p}}$

$\mathrm{k}$

$\dot{m}$

q

$\dot{Q}$

$\mathrm{P}$

$\mathrm{T}$

$\mathrm{x}, \mathrm{y}, \mathrm{z}$

$\mathrm{u}, \mathrm{v}, \mathrm{w}$

\section{Greek Symbols}

$\beta$

$\Delta \mathrm{T}$

$\varepsilon$

$\mu$

$\rho$
Total heat transfer area, $\mathrm{cm}^{2}$

Specific heat rate, $\mathrm{W} / \mathrm{K}$

Specific heat, $\mathrm{kJ} / \mathrm{kg}-\mathrm{K}$

Heat transfer coefficient, $\mathrm{W} / \mathrm{m}-\mathrm{K}$

Mass flow rate, $\mathrm{kg} / \mathrm{s}$

Heat flux, W/m ${ }^{2}$

Heat transfer rate, $\mathrm{W}$

Pressure, bar

Temperature, ${ }^{\circ} \mathrm{C}$

Spatial coordinates, $\mathrm{m}$

Velocities, $\mathrm{m} / \mathrm{s}$

Groove angle of the plate, ${ }^{\circ}$

Temperature difference, ${ }^{\circ} \mathrm{C}$

Effectiveness

Dynamic viscosity, Pa-s

Density, $\mathrm{kg} / \mathrm{m}^{3}$ 
Kutay Aydın et al. / Energy Research Journal 2017, 8 (2): 22.31

DOI: 10.3844/erjsp.2017.22.31

\section{Subscripts}

B

$\mathrm{i}, \mathrm{j}, \mathrm{k}$

in

$\max$

$\min$

out

$\mathrm{Ti}$

w

\section{Abbreviations}

AISI

CAM

CFD

NTU

SST
Geothermal fluid/geofluid or brine Directions

Inlet

Maximum

Minimum

Outlet

Titanium

Water

American iron and steel institute

Computer aided modelling

Computational fluid dynamics

Number of transfer units

Shear stress transport 